\title{
Authorship: From credit to accountability - Reflections from the Editors' network
}

\author{
Fernando Alfonso ${ }^{1 *}$, Parounak Zelveian², Jean-Jacques Monsuez ${ }^{3}$, Michael Aschermann ${ }^{4}$, \\ Michael Boehm ${ }^{5}$, Alfonso Buendía-Hernández ${ }^{6}$, Tzung-Dau Wang ${ }^{7}$, Ariel Cohen ${ }^{8}$, Sebija Izetbegovic ${ }^{9}$, \\ Anton Doubel/ ${ }^{10}$, Dario Echeverri ${ }^{11}$, Nuray Enç ${ }^{12}$, Ignacio Ferreira-González ${ }^{13}$, Anetta Undas ${ }^{14}$, \\ Ulrike Fortmüller ${ }^{15}$, Plamen Gatzov' ${ }^{16}$, Carmen Ginghina ${ }^{17}$, Lino Goncalves ${ }^{18}$, Faouzi Addad ${ }^{19}$, \\ Mahmoud Hassanein ${ }^{20}$, Gerd Heusch ${ }^{21}$, Kurt Huber ${ }^{22}$, Robert Hatala ${ }^{23}$, Mario Ivanusa ${ }^{24}$, Chu-Pak Lau ${ }^{25}$, \\ Germanas Marinskis ${ }^{26}$, Livio Dei-Cas ${ }^{27}$, Carlos E. Rochitte ${ }^{28}$, Kjell Nikus ${ }^{29}$, Eckart Fleck ${ }^{30}$, Luc Pierard ${ }^{31}$, \\ Slobodan Obradović32, María del P. Aguilar-Passano ${ }^{33}$, Yangsoo Jang ${ }^{34}$, Olaf Rødevand ${ }^{35}$, \\ Mikael Sander ${ }^{36}$, Evgeny Shlyakhto ${ }^{37}$, Çetin Ero ${ }^{38}$, Dimitris Tousoulis ${ }^{39}$, Dilek Ural ${ }^{40}$, Jan J. Piek ${ }^{41}$, \\ Albert Varga ${ }^{42}$, Andreas J. Flammer/François Mach ${ }^{43}$, Alban Dibra ${ }^{44}$, Faiq Guliyev ${ }^{45}$, Alexander Mrochek ${ }^{46}$, \\ Mamanti Rogava ${ }^{47}$, Ismael Guzmán-Melgar ${ }^{48}$, Giuseppe Di Pasquale ${ }^{49}$, Kanat Kabdrakhmanov ${ }^{50,}$ \\ Laila Haddour ${ }^{51}$, Zlatko Fras ${ }^{52}$, Claes Held ${ }^{53}$ and Valentyn Shumakov ${ }^{54}$
}

${ }^{1}$ Chairman Editors' Network; 'Editor in Chief Scientific Medical Journal; ${ }^{3} E d i t o r$ in Chief Archives des maladies du cœur et des vaisseaux-Pratique; ${ }^{4}$ Editor in Chief Cor et Vasa; ${ }^{5}$ Editor in Chief Clinical Research in Cardiology; ${ }^{6}$ Editor in Chief Archivos de Cardiología de México; ${ }^{7}$ Editor in Chief Acta Cardiológica Sinica; ${ }^{8}$ Editor in Chief Archives of Cardiovascular Diseases; ${ }^{9}$ Editor in Chief Medicinski Zurnal; ${ }^{10}$ Editor in Chief SA Heart; ${ }^{11}$ Editor in Chief Revista Colombiana de Cardiología; ${ }^{12}$ Editor in Chief Kardiyovaskuler Hemsirelik Dergisi; ${ }^{13}$ Editor in Chief Revista Española de Cardiología; ${ }^{14}$ Editor in Chief Kardiologia Polska; ${ }^{15}$ Editor in Chief Cardio News; ${ }^{16}$ Editor in Chief Bulgarian Journal of Cardiology; ${ }^{17}$ Editor in Chief Romanian Journal of Cardiology; ${ }^{18}$ Editor in Chief Revista Portuguesa de Cardiología; ${ }^{19}$ Editor in Chief Revue Tunisienne de Cardiologie; ${ }^{20}$ Editor in Chief The Egyptian Heart Journal; ${ }^{21}$ Editor in Chief Basic Research in Cardiology; ${ }^{22}$ Editor in Chief Austrian Journal of Cardiology; ${ }^{23}$ Editor in Chief Cardiology Letters;

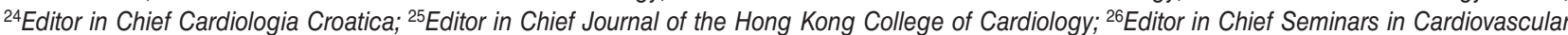
Medicine; ${ }^{27}$ Editor in Chief Journal of Cardiovascular Medicine; ${ }^{28}$ Editor in Chief Arquivos Brasileiros de Cardiologia; ${ }^{29}$ Editor in Chief Sydänääni (Heart Beat); ${ }^{30}$ Editor in Chief Der Kardiologe; ${ }^{31}$ Editor in Chief Acta Cardiologica; ${ }^{32}$ Editor in Chief Heart and Blood Vessels; ${ }^{33}$ Editor in Chief Revista Uruguaya de Cardiología; ${ }^{34}$ Editor in Chief Korean Circulation Journal; ${ }^{35}$ Editor in Chief Hjerteforum; ${ }^{36}$ Editor in Chief Cardiologisk Forum; ${ }^{37}$ Editor in Chief Russian Journal of Cardiology; ${ }^{38}$ Editor in Chief Anatolian Journal of Cardiology; ${ }^{39} \mathrm{Editor}$ in Chief Hellenic Journal of Cardiology; ${ }^{40}$ Editor in Chief Archives of the Turkish Society of Cardiology; ${ }^{41}$ Editor in Chief Netherlands Heart Journal; ${ }^{42}$ Editor in Chief Cardiologia Hungarica; ${ }^{43}$ Editor in Chief Cardiovascular Medicine; ${ }^{44}$ Editor in Chief Revista Shqiptare e Kardiologjisë; ${ }^{45}$ Editor in Chief Azerbaijan Journal of Cardiology; ${ }^{46}$ Editor in Chief Cardiology in Belarus; ${ }^{47}$ Editor in Chief Cardiology and Internal Medicine (Georgian International Society of Cardiomyopathy); ${ }^{48}$ Editor in Chief Revista Guatemalteca de Cardiología; ${ }^{49}$ Editor in Chief Giornale Italiano di Cardiologia; ${ }^{50}$ Editor in Chief Journal Terapevticheskiy vestnic; ${ }^{51}$ Editor in Chief Revue Marocaine de Cardiologie; ${ }^{52}$ Editor in Chief Slovenska kardiologija; ${ }^{53}$ Editor in Chief Svensk Kardiologi; ${ }^{54}$ Editor in Chief Ukrainian Journal of Cardiology.

On behalf of the Editors' Network, European Society of Cardiology Task Force.

This is a joint simultaneous publication initiative involving all interested National and Affiliated Cardiovascular Journals of the European Society of Cardiology.

\begin{abstract}
The Editors' Network of the European Society of Cardiology (ESC) provides a dynamic forum for editorial discussions and endorses the recommendations of the International Committee of Medical Journal Editors (ICMJE) to improve the scientific quality of biomedical journals. Authorship confers credit and important academic rewards. Recently, however, the ICMJE
\end{abstract}


emphasized that authorship also requires responsibility and accountability. These issues are now covered by the new (fourth) criterion for authorship. Authors should agree to be accountable and ensure that questions regarding the accuracy and integrity of the entire work will be appropriately addressed. This review discusses the implications of this paradigm shift on authorship requirements with the aim of increasing awareness on good scientific and editorial practices.

Key words: Editorial ethics. Scientific Process. Authorship. Accountability. Scientific Journals. Journals.

\section{Introduction}

The Editors' Network of the European Society of Cardiology (ESC) is committed to foster implementation of high-quality editorial standards among ESC National Society Cardiovascular Journals (NSCJ) ${ }^{1-6}$. NSCJ plays a major role not only in disseminating original scientific research worldwide but also in education and harmonization of clinical practice ${ }^{2-6}$. Promoting editorial excellence is paramount to increase the scientific prestige of $\mathrm{NSCJ}^{1-6}$. In this regard, the Editors' Network endorses the recommendations of the International Committee of Medical Journal Editors (ICMJE) ${ }^{1}$. The ICMJE continuously updates its document on uniform requirements (previously known as the Vancouver guidelines) for manuscripts submitted to biomedical journals. These include recommendations for the conduct, reporting, editing, and publication of scholarly work. Notably, vexing ethical issues are gaining increasing editorial relevance ${ }^{1}$.

Biomedical research relies on trust and transparency of the scientific process where authors remain center stage ${ }^{1,7-9}$. This review will discuss the new recommendations on authorship issued by the ICMJE ${ }^{1,10,11}$ with the aim of providing further editorial insight to be progressively implemented by the NSCJ.

\section{New authorship requirements}

In August 2013, an important revision of the ICMJE recommendations included a fourth criterion for authorship to emphasize each author's responsibility to stand by the integrity of the entire work ${ }^{1,10,11}$. Classically, the ICMJE requirements for authorship included (1) substantial contributions to the conception or design of the work or the acquisition, analysis, or interpretation of data for the work; (2) drafting the work or revising it critically for important intellectual content; and (3) final approval of the version to be published. In the updated ICMJE requirements, a new (fourth) criterion also should be met ${ }^{1}$. This novel requirement for authorship includes an agreement to be accountable for all aspects of the work and ensures that questions related to the accuracy or integrity of any part of the work are appropriately investigated and resolved ${ }^{1}$. The essence of this new requirement is that it helps to balance credit with responsibility ${ }^{10}$. With this revision, the ICMJE emphasizes that authorship is a serious commitment to accountability. Now all four conditions must be met by each individual author ${ }^{1}$. The addition of a fourth criterion was motivated by situations in which some authors were unable to, or refused to, respond to inquiries on potential scientific misconduct regarding certain aspects of the study or by denying any responsibility ${ }^{1,10-14}$. Editors occasionally face reluctant authors who try to distance themselves from a conflictive publication and shift responsibilities elsewhere ${ }^{11}$. The main novel idea is to emphasize the responsibility of each author to stand for the integrity of the entire work. Each author of a scientific paper needs to understand the full scope of the work, know which coauthors are responsible for specific contributions and have confidence in coauthors' ability and integrity ${ }^{1,10-14}$. Should questions arise regarding any aspect of a study, the onus is on all authors to investigate and ensure resolution of the issue, which is then to be presented to the corresponding editor ${ }^{1,10-14}$.

To better appraise this fourth criterion, the precise meaning of responsibility and accountability should be revisited. Responsibility is defined as the moral obligation to ensure that a particular task is adequately performed ${ }^{15,16}$. Accordingly, responsibility relates to tasks that have been assigned to an individual ${ }^{15,16}$. By contrast, accountability denotes the duty to justify a given action to others and to respond for the results of that action $^{15,16}$. Therefore, accountability mainly relates to the awareness and assumption of the role of being the one to blame if things go wrong ${ }^{15,16}$. Nevertheless, oftentimes, responsibility is used interchangeably with accountability ${ }^{15,16}$.

Claiming that each individual author is held morally responsible in every case that misconduct is detected would appear unreasonable considering the complexity of current research. Rather, the fourth criterion suggests that each author must cooperate to clarify misconduct-related issues if the paper is called into question ${ }^{1,16}$. 


\section{Research credits}

Acceptance and publication of a scientific paper are always a cause of major celebration among authors ${ }^{11}$. Authorship provides prestige, credit, and scientific recognition. Authorship has important academic, social, and financial implications ${ }^{1,11}$. Currently, authorship remains a major criterion for promotion and career advancement among scholars. Publication records are revised in depth for university tenures and job appointments. A total number of publications and citations remain currencies widely used to ascertain the academic value of individual investigators. In this regard, the ICMJE recommendations on authorship are intended to ensure that anybody who has made a "substantive" intellectual contribution to a paper is given credit as an author ${ }^{1}$.

\section{Potential problems derived from publication of research}

Publication of a scientific paper usually marks the end of a research project and opens a time for discussion and criticism or acceptance by the scientific community ${ }^{11}$. Occasionally, the healthy scientific debate fuelled by the publication of the paper raises serious concerns. In rare cases, even the integrity of the research or published paper is brought into question ${ }^{11}$. In these situations, authors may try to escape from the embarrassment of publishing a scientifically flawed study. This explains why the new fourth criterion is so pertinent to address issues related to scientific misconduct. Should irregularities be confirmed, editors must report to the authors' academic institution and, eventually, to the readers, with expressions of concern, or in the worst case scenario, with a retraction of the published paper ${ }^{1}$.

\section{Considerations on classical authorship criteria}

Any researcher listed as an author should have made a "substantive" intellectual contribution to the study and be prepared to take public responsibility for the work, ensure its accuracy, and be able to identify his/her contribution to the study ${ }^{1}$. However, a problem with the definition of authorship involves the subjectivity in what constitutes a "substantial" contribution to the research or the manuscript. In fact, the precise threshold of involvement required to qualify for authorship remains unclear. As the real problem lies in defining what represents a "substantial" contribution, means to quantify the actual work performed by individual authors have been proposed. In this regard, it has been suggested $^{17}$ that substantial contribution to a publication consists of an important intellectual contribution without which, a part of the work or even the entire work, could not have been completed or the manuscript could not have been written ${ }^{17}$.

According to the $\mathrm{ICMJE}^{1}$, persons who do not qualify as an author include those who "only" provide: (1) recruitment of patients to a trial, (2) general data collection, (3) obtaining samples for a study, (4) acquisition of funding, (5) general supervision of the research group by the department chairperson. Conversely, persons who significantly contributed to the paper but do not meet the four criteria for authorship should be listed in the acknowledgment section after obtaining their consent.

\section{Publishing individual contributions}

The ICMJE authorship guidance is intentionally broad and open to accommodate the diversity of scientific research and allow space for the specific editorial policies of individual journals ${ }^{1}$. However, many have requested a more structured authorship framework to improve consistency and clarity in authorship requirements. The best means to present the relationship between authorship and intellectual involvement in research remain an issue of ongoing debate. Currently, the ICMJE does not mandate that all authors communicate exactly what "contributions" qualify them to be an author'. However, unless authorship reflects to what extent individual researchers have been intellectually involved in the work, it will remain misleading regarding relative research merits. Honesty and openness in attribution ensure fairness in credit. Many editors argue that authorship criteria should be revised to request a contribution declaration, to fully capture deserving authorship and credit. Accordingly, to promote transparency and remove ambiguity on specific contributions, editors are now strongly encouraged to develop and implement contributorship policies in their journals ${ }^{1}$. As discussed, however, the question regarding the quality and quantity of contribution required to qualify an individual for authorship remains unresolved ${ }^{1}$. An interesting proposal in this regard suggests including contributorship badges. These badges are designed to fully capture the different types of collaboration in the submitted work that, otherwise, will be difficult to recognize with traditional credentials. Contributors' listing allows 
a more accurate and granular assessment of credit. In addition, this strategy provides additional insight on contributor-adjusted productivity ${ }^{18}$. Ideally, each ICMJE criterion should have at least one badge. Each badge includes a list of authors making a contribution to that specific role ${ }^{18-20}$. Others have proposed the value of assigning a numerical value to better evaluate the degree of relative contributions and, eventually, to create a contribution-specific index for each author to better assess research productivity ${ }^{18-20}$.

Detailing authors' contributions inform the readers of the nature of the individual work and avoid diluting credits by precisely allocating merits. In multi-authored papers, it is, particularly, important that authors state the specific role that they played in the research. Each research represents a significant amount of effort and, on average, the larger the number of authors, the smaller percentage of effort for a given author. Other forms of contributions, not fulfilling criteria for authorship, may be recognized in the acknowledgment section or by listing these people as collaborators. This is an important issue considering the ever increasing number of authors seen in recent publications that represent a paradigm shift resulting from teamwork research $^{18-24}$. Contributors credited as authors should take full responsibility and remain accountable for what is published ${ }^{1,18}$. In this regard, contribution-adjusted credits can be further weighted by other factors to derive more effective parameters for measuring research productivity. Currently, every coauthor gets the exact amount of citation credit regardless of their contribution. Therefore, an "author matrix" (including participation in ideas, work, writing, and stewardship) has been proposed to "quantify" individual contributions and roles in multiauthored papers ${ }^{18-24}$.

\section{Byline location and hierarchy}

There is no adequate guidance for author sequence in the byline. In fact, practices to clarify the relative merit of the different coauthors in a manuscript vary significantly among scientific disciplines ${ }^{18-22}$. For biomedical journals, the first author is the most important position, followed by the last author and then the second author. The first author is reserved for the person who made the largest contribution (investing most time in the project) usually the author who wrote the first draft of the paper. Then, the sequence of authors tends to represent progressively lesser contributions ${ }^{18}$. Following this approach, where the sequence determines credit, the last author receives the least. Accordingly, the last position might be considered as a rather generous option. Actually, the last position is currently considered as very important in biomedical research, and in fact, it is frequently associated with the corresponding author or the guarantor of the entire work ${ }^{18}$. However, many argue that senior scientists should grab the pen (keyboard) more often as writing remains essential for advancement in knowledge ${ }^{19}$. Senior authors have the responsibility to promote the academic career of new generation scientists.

Many journals allow authors to declare that two or more individuals have made "equal contribution" to the research ${ }^{21,25-28}$. In the last decade, the percentage of articles with equal contribution statements has increased dramatically both in basic and medical scientific journals ${ }^{25}$. Notably, the designation of "joint first-authors" should be based on the quality and quantity of the work ${ }^{21,25-28}$. Thus, the "contributed equally" designation should be reserved to honestly reflect similar scientific contributions and not to inflate a curriculum $v^{2}$ itae $^{21,25-28}$. Interestingly, the practice of listing two individuals as "joint last author" is used less frequent but steadily increasing. These publications should include a footnote, clearly indicating that both authors equally contributed to the work ${ }^{21,25-28}$.

The corresponding author takes primary responsibility for communication with the journal during the submission, peer-review, publication, and post-publication periods ${ }^{1}$. Currently, most journals require contact e-mail addresses from all listed authors who then will be contacted to inform that the corresponding author submitted the paper. This ensures that they are aware that the paper has been submitted in their name. The systematic implementation of this electronic warning system paves the way to guarantee that the third authorship criterion has been met. Therefore, the policy now may be considered as a mere administrative requirement similar to the signing of a copyright transfer.

The "guarantor" of the study may be different from the first or corresponding author and frequently is the principal investigator or more senior person in the group. The guarantor takes full responsibility for the integrity of the work as a whole from inception to the published paper. Accordingly, the guarantor must be fully prepared to defend all parts of the research project and the final manuscript. Guarantors vouching for the integrity of the entire work are of special value for multiauthor articles particularly when many institutions are involved. All authors should also disclose potential conflicts of interest ${ }^{1,5}$. The ICMJE uniform conflict of interest disclosure has been recently 
updated and all authors should complete the corresponding standardized individual electronic document $^{1,5}$. In particular, authors of sponsored studies should indicate that they had full access to the data and take complete responsibility for the accuracy and integrity of the analysis. This is important as roles and interests of different stakeholders may remain elusive or misleading in this type of the study 1 .

The subjectivity and emotionality of authorship may explain why disputes among investigators are not uncommon. Authorship disputes among research teams should be avoided by deciding roles and responsibilities beforehand. Ideally, the order of authors should be collectively decided by the research team at the onset of the project ${ }^{29}$. Then, the definitive author order should be revised when the work is completed, taking into account the actual level of individual contributions ${ }^{17}$. Editors are unable to judge whether authors have met the authorship criteria. The Committee on Publication Ethics (www.publicationethics.org) guidelines are useful to solve publication disputes ${ }^{9}$. Editors should seek explanations and signed agreement of all authors in case of a request for a change in the author list ${ }^{1}$.

\section{Multiauthored articles}

Scientific collaboration has become increasingly important because the complexity of modern research involves different competencies ${ }^{16}$. Moreover, a large number of patients and centers may be required to adequately address clinically relevant questions ${ }^{16}$. In addition, multidisciplinary research groups offer the opportunity of cross-pollination ${ }^{16}$. Therefore, teamwork is currently commonplace in biomedical research. Coauthorship is the most tangible result of multilateral scientific collaboration. Group (corporate) authorship has become increasingly common with variations in how individual authors and research group names are listed in the byline. Notably, citation impact is greater in papers with multiple authors coming from international cooperation. The problem of inflating publication and citation records of authors participating in multicenter studies has been a cause of concern ${ }^{18}$. This is due, at least in part, to collaboration-induced self-citation ${ }^{30}$. Salami publications, or least publishable unit strategies, are initiatives that inflate the number of publications on the same research project by dividing the work (that could have been presented in a single main paper) into smaller component parts and then publishing them as several different articles. Such strategies may be detected in some multicenter studies ${ }^{30}$. The use of coauthor-adjusted citation indexes has been suggested to account for this phenomenon ${ }^{30}$.

There is evidence that the number of coauthors per paper in medical literature has increased exponentially over time ${ }^{22,31}$. The reason for this increase is probably multifactorial and includes, increasing complexity of research, as discussed, but also author inflation. Inappropriate authorship is not ethical and eventually leads to diminish the value of authorship, generating a situation where undeserved coauthors cannot take responsibility for the research ${ }^{22,31}$. Interestingly, the correlation between research quality and number of authors is poor, suggesting that the component of author inflation plays a greater role than that of research complexity ${ }^{31}$.

Until now, the number of authors in the byline was not considered in the evaluation of the relative academic merit of individual authors ${ }^{3}$. However, as a research project involves a defined amount of work, the larger the number of authors in a paper, the smaller the merit that deserves any given author. Major efforts are made by some individuals, whereas others contribute significantly less. The credit received by people doing the work becomes diluted by the inclusion of many authors with little, if any, contributions. Eventually, this "free lunch" strategy undermines the value of being named on a scientific paper ${ }^{32}$.

Authorship guidelines should be updated to adapt to the growing trend of collaborative research. The larger the number of authors, the more opportunities for contentious arguments and disputes. Every author of a "group authorship" work must meet the four criteria for authorship. Otherwise, they should be identified just as investigators or collaborators rather than authors ${ }^{1}$. Given the complexity and multiple tasks involved in current research, it is clear that most authors cannot participate in every aspect of the work. Accordingly, specific responsibilities should be tied to different research roles. Authors should refrain from collaborating with colleagues whose quality or integrity may inspire concerns ${ }^{1}$. Last but not least, with a growing number of authors, it is increasingly difficult to identify those who may be held morally responsible should scientific misconduct be detected ${ }^{22,31}$. Holding everybody responsible is unfair to the researchers that are not guilty of misconduct.

\section{Breaches in authorship: from ghost to guest authors}

Breaches in authorship are a form of deception. Guest or gift (honorary) and ghost (hidden) authors 
represent a form of authorship abuse that should not be permitted ${ }^{33-37}$. Ghost authorship is omitting authors who have made relevant contributions to a paper. Ghost authors provide contributions to a manuscript who do merit authorship but, for different reasons, are not included in the author byline. Some ghost authors may have major conflicts of interest or are paid by a commercial sponsor. This should be differentiated from ghostwriting. Ghostwriters are writing contributors to a manuscript that do not fulfill authorship criteria, but their contributions are not disclosed in the acknowledgments ${ }^{17,36}$. Ghostwriting is also an unethical practice as it keeps hidden the involvement in the manuscript. The concern is that writers hired by the industry might influence the content of the publication or hide unwelcome results, which introduces potential bias that is obscured when relevant academic guest authors are accredited with authorship ${ }^{17}$. Professional medical writers should follow ethical publication practices and should openly disclose their involvement in the acknowledgment section ${ }^{36}$.

The inclusion of individuals with minimal or no input reflects "loose authorship" practices ${ }^{33-37}$. Guest, gift, or honorary authorship is defined as coauthorship awarded to people who do not meet the authorship criteria and have not contributed substantially to take public responsibility for the work ${ }^{1}$. This may be offered in the belief that the prestige of a scientifically respected person will increase the likelihood of publication or the impact of the work ${ }^{29}$. Oftentimes, a well-known academic senior name is used to conceal ghost authors with industry-related conflicts of interest ${ }^{29}$. Both, the gift author and the remaining coauthors may benefit from this practice (a win-win situation) that, nevertheless, remains unethical. The increased pressure for publishing among scholars seeking promotion and career advancement (the "publish or perish" culture) may also help to explain these practices. This pressure explains why some researchers accept the "gift" authorship in papers to which they have not contributed intellectually. This abuse in authorship devalues the merit of being named as an author in a scientific paper. As previously discussed, quantitative contribution helps to prevent granting undeserved credits to guest authors who take away well-deserved credits from the authors who actually did the work ${ }^{37-40}$.

Studies suggest that breaches of authorship guidelines are frequent. In a recent survey, one-third of authors believed that they had been excluded from deserved authorship and a similar number declared that they had experienced pressures to include undeserved authors in their papers ${ }^{20}$. Another recent study of journals included in the Journal Citation Report database suggested that $85 \%$ of them included in their policy guidance the requirement that authors should be accountable for the research as a whole, 32\% explicitly prohibited guest or ghost authorship but only $5 \%$ required authors to describe their individual contributions ${ }^{25}$.

\section{Final remarks}

Authorship not only confers credit but also involves responsibility. Authors should be accountable and vouch for the integrity of the entire work. The Editors' Network of the ESC endorses the ICMJE recommendations on authorship and encourages individual NSCJ to adapt their editorial policies accordingly.

\section{Disclosures}

None of the Editors authors of this paper have any potential conflict of interest that needs to be disclosed in relation to this manuscript.

\section{Acknowledgments}

We are grateful for the support and assistance of Michael Alexander and Margot Bolard, from the ESC Publications Department, at the European Heart House.

\section{References}

1. The International Committee of Medical Journals Editors. Recommendations for the Conduct, Reporting, Editing, and Publication of Scholarly Work in Medical Journals. Available from: http://www.icmje.org/recommendations.

2. Lüscher TF. The codex of science: honesty, precision, and truth-and its violations. Eur Heart J. 2013;34:1018-23.

3. Alfonso F, Ambrosio G, Pinto FJ, et al. European society of cardiology national cardiovascular journals: the 'editors' network'. Eur Heart J. 2010;31:26-8.

4. Mills $P$, Timmis $A$, Huber $K$, et al. The role of European national journals in education. Heart. 2009;95:e3.

5. Alfonso F, Timmis A, Pinto FJ, et al. Conflict of interest policies and disclosure requirements among European society of cardiology national cardiovascular journals. Eur Heart J. 2012;33:587-94.

6. Alfonso F. Data sharing. Editors' network European society of cardiology task force. Eur Heart J. 2017;38:1361-3.

7. Council of Science Editors. White Paper on Publication Ethics. CSE's White Paper on Promoting Integrity in Scientific Journal Publications; 2012. Available from: http://www.CouncilScienceEditors.org.

8. World Association of Medical Editors. WAME Professionalism Code of Conduct the New WAME Professionalism Code of Conduct for Medical Journal Editors. Available from: http://www.wame.org.

9. Committee on Publication Ethics. COPE. Code of Conduct and Best Practice Guidelines for Journal Editors. Available from: http://www.publicationethics.org/resources/guidelines.

10. Stephenson J. ICMJE: all authors of medical journal articles have responsibility to stand by the integrity of the entire work. JAMA. 2013; 310:1216

11. Authorship and accountability. Lancet. 2013;382:744.

12. Goodman NW. Survey of fulfillment of criteria for authorship in published medical research. BMJ. 1994;309:1482. 
13. Rennie D, Flanagin A. Authorship! authorship! guests, ghosts, grafters, and the two-sided coin. JAMA. 1994;271:469-71.

14. Rennie D, Yank V, Emanuel L. When authorship fails. A proposal to make contributors accountable. JAMA. 1997;278:579-85.

15. Leonelli S. Locating ethics in data science: responsibility and accountability in global and distributed knowledge production systems. Philos Trans A Math Phys Eng Sci. 2016;374:20160122.

16. Helgesson G, Eriksson S. Responsibility for scientific misconduct in collaborative papers. Med Health Care Philos. 2018;21:423-30.

17. Stocks A, Simcoe D, Toroser D, DeTora L. Substantial contribution and accountability: best authorship practices for medical writers in biomedical publications. Curr Med Res Opin. 2018;34:1163-8.

18. Clement TP. Authorship matrix: a rational approach to quantify individual contributions and responsibilities in multi-author scientific articles. Sci Eng Ethics. 2014;20:345-61.

19. Fairbairn S, Kelly L, Mahar S, Prosée R. Authorship: an evolving concept. Editorial Coordinators. Health Learning, Research and Practice, Wolkers and Kluber. Available from: http://www.wkauthorservices.editage.com/ resources/files/An_Evolving_Concept_in_Scientific_and_Medical_Publishing.pdf.

20. Nylenna M, Fagerbakk F, Kierulf P. Authorship: attitudes and practice among Norwegian researchers. BMC Med Ethics. 2014;15:53.

21. Scientific Integrity Committee of Swiss Academies of Arts and Sciences, Hess CW, Brückner C, et al. Authorship in scientific publications: analysis and recommendations. Swiss Med Wkly. 2015;145:w14108.

22. Hwang SS, Song $\mathrm{HH}$, Baik JH, et al. Researcher contributions and fulfiIIment of ICMJE authorship criteria: analysis of author contribution lists in research articles with multiple authors published in radiology. International committee of medical journal editors. Radiology. 2003;226:16-23.

23. Hoen WP, Walvoort HC, Overbeke AJ. What are the factors determining authorship and the order of the authors' names? A study among authors of the Nederlands tijdschrift voor geneeskunde (Dutch journal of medicine). JAMA. 1998;280:217-8.

24. Wager E. Do medical journals provide clear and consistent guidelines on authorship? MedGenMed. 2007:9:16.

25. Resnik DB, Tyler AM, Black JR, Kissling G. Authorship policies of scientific journals. J Med Ethics. 2016;42:199-202.
26. Akhabue E, Lautenbach E. "Equal" contributions and credit: an emerging trend in the characterization of authorship. Ann Epidemiol. 2010;20:868-71.

27. Dotson B. Equal contributions and credit assigned to authors in pharmacy journals. Am J Pharm Educ. 2013;77:39.

28. Li Z, Sun YM, Wu FX, et al. Equal contributions and credit: an emerging trend in the characterization of authorship in major anaesthesia journals during a 10-yr period. PLoS One. 2013;8:e71430.

29. Tarkang EE, Kweku M, Zotor FB. Publication practices and responsible authorship: a review article. J Public Health Afr. 2017;8:723.

30. Ioannidis JP. A generalized view of self-citation: direct, co-author, collaborative, and coercive induced self-citation. J Psychosom Res. 2015; 78:7-11.

31. Chow DS, Ha R, Filippi CG. Increased rates of authorship in radiology publications: a bibliometric analysis of 142,576 articles published worldwide by radiologists between 1991 and 2012. AJR Am J Roentgenol. 2015;204:W52-7.

32. Shapiro DW, Wenger NS, Shapiro MF. The contributions of authors to multiauthored biomedical research papers. JAMA. 1994;271:438-42.

33. Flanagin A, Carey LA, Fontanarosa PB, et al. Prevalence of articles with honorary authors and ghost authors in peer-reviewed medical journals. JAMA. 1998;280:222-4.

34. Laine C, Mulrow CD. Exorcising ghosts and unwelcome guests. Ann Intern Med. 2005;143:611-2.

35. Wislar JS, Flanagin A, Fontanarosa PB, Deangelis CD. Honorary and ghost authorship in high impact biomedical journals: a cross sectional survey. BMJ. 2011;343:d6128.

36. Stretton S. Systematic review on the primary and secondary reporting of the prevalence of ghostwriting in the medical literature. BMJ Open. 2014;4:e004777.

37. Smith R. Let's simply scrap authorship and move to contributorship. BMJ. 2012;344:e157.

38. Tilak G, Prasad V, Jena AB. Authorship inflation in medical publications. Inquiry. 2015;52:0046958015598311.

39. Juyal D, Thawani V, Thaledi S, Prakash A. The fruits of authorship. Educ Health (Abingdon). 2014;27:217-20.

40. Fanelli D. Why growing retractions are (mostly) a good sign. PLoS Med. 2013;10:e1001563. 